[RADIOCARBON, VOL. 29, NO. 1, 1987, P 156-158]

\title{
DRASTIC INCREASE OF BACKGROUND IN THE GLIWICE RADIOCARBON LABORATORY DURING LATE APRIL, 1986, AND ITS TIME CHANGES*
}

\author{
MIECZYSKAW F PAZDUR and ANDRZEJ ZASTAWNY
}

Radiocarbon Laboratory, Institute of Physics, Silesian Technical University, Krzywoustego 2, PL-44-100 Gliwice, Poland

ABSTRACT. Preliminary observations of changes of the background of three proportional counters during May and June, 1986, are presented. Some isotopes contributing to the rise of background were identified on the basis of their half-life determinations.

Starting from April 29, 1986, a significant increase of the background of proportional counters in the Radiocarbon Laboratory in Gliwice, caused by damage to a nuclear power plant in Chernobyl near Kiev, USSR, was noted. An analysis of this increase during the first three months is presented for different proportional counters.

Three proportional counters are used for natural radiocarbon measurements in our laboratory. Each counter forms a separate unit with its own anticoincidence and material shielding. All units are located in the same semi-underground room. Basic parameters of the units are given in Table 1 (see also Pazdur et al, 1982). An increase of the background counting rate was noted on counter No. 1 (L1) late morning, April 30. This counter was filled a day before with inactive $\mathrm{CO}_{2}$ for routine background counting rate measurement. The same gas was left in this counter till the end of May. Two others were filled with inactive $\mathrm{CO}_{2}$ a few days later. The resulting record of background counting rate changes is shown in Figure 1. A rapid increase of background of counter No. 1 on April 29 and 30 should be noted with the rate exceeding $1.5 \mathrm{cpm}$ per hour. The maximum of this peak was not detected, but it occurred perhaps on May 1. Mean counting rate recorded from April 30 to May 2 was equal to ca $42 \mathrm{cpm}$, $i e$, ca 6 times greater than before contamination. Ca $10 \%$ of partial results were rejected as outliers by a statistical microcomputer program gathering the data (Walanus, 1986). Thus, we conclude that the peak value was greater, but not more than by some $10-20 \%$ of the recorded mean value. Maximum increase of background of counters No. 2 and 3 was estimated at ca $6 \mathrm{cpm}$ and $1.2 \mathrm{cpm}, i e$, ca $100 \%$ and $60 \%$ of the pre-contamination levels, respectively. Possible explanation of these differences is in the fact that counters No. 2 and 3 have internal shielding made of a layer of old lead (counter No.

TABLE 1

Parameters of the proportional counters

\begin{tabular}{ccclll}
\hline $\begin{array}{c}\text { Counter } \\
\text { no. }\end{array}$ & $\begin{array}{c}\text { Total } \\
\text { volume } \\
\left(\mathrm{dm}^{3}\right)\end{array}$ & $\begin{array}{c}\mathrm{CO}_{2} \\
\text { pressure } \\
(\mathrm{mm} \mathrm{Hg})\end{array}$ & Cathode & Position & $\begin{array}{c}\text { Background } \\
(\mathrm{cpm})\end{array}$ \\
\hline 1 & 2.9 & 1700 & Steel & Vertical & $7.014 \pm 0.050$ \\
2 & 4.5 & 1700 & Copper & Horizontal & $6.030 \pm 0.050$ \\
3 & 1.5 & 760 & Copper & Horizontal & $1.896 \pm 0.030$ \\
\hline
\end{tabular}
versity.

*This study was sponsored by Central Research Project CPBP 01.06 from Warsaw Uni- 


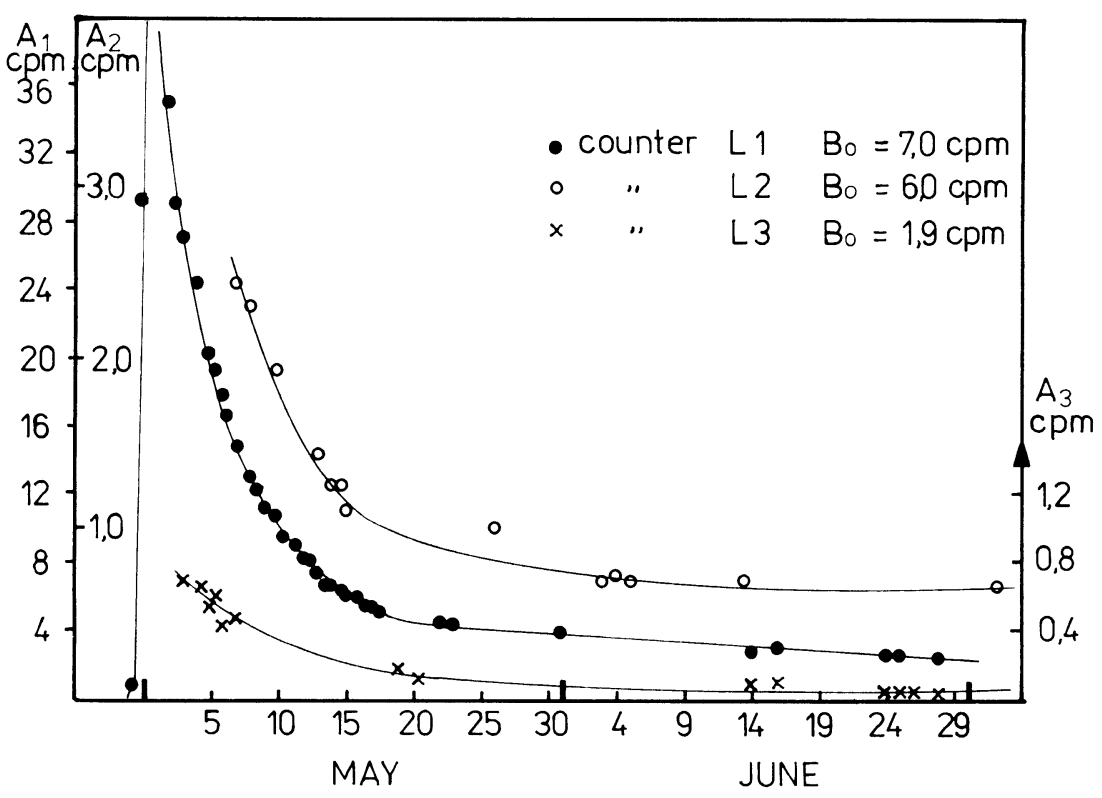

Fig 1. Increase of background above the pre-contamination level

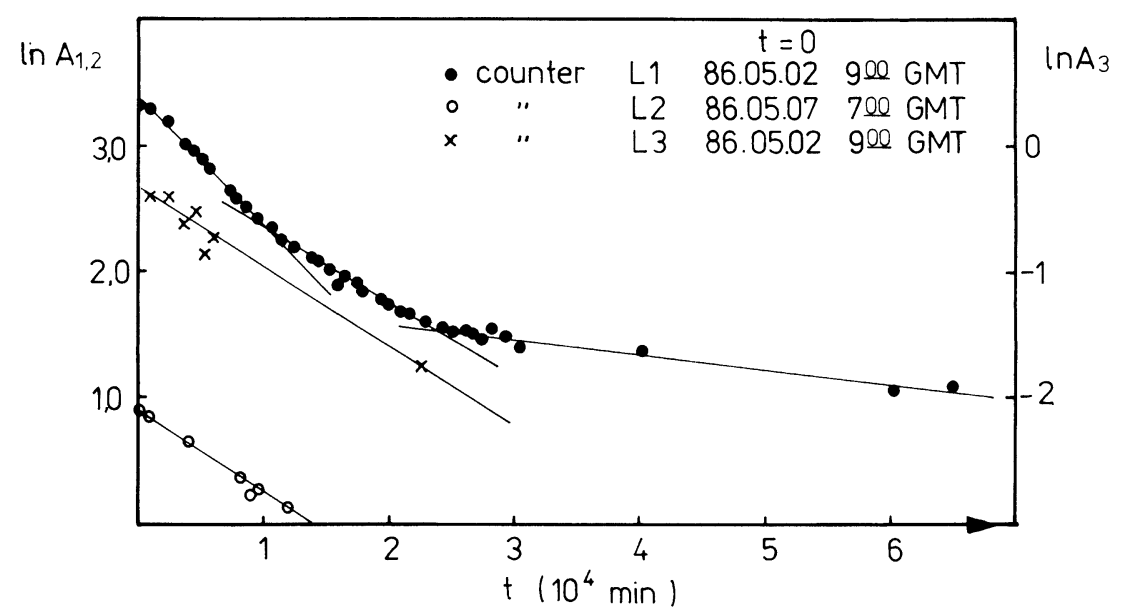

Fig 2. Semilogarithmic plot of post-contamination changes of background counting rate in different counters 
2) and of purified mercury (counter No. 3), and moreover, both units are tightly covered with plastic foil.

Post-contamination decrease of background counting rate of all units is shown in Figure 2 in a semilogarithmic plot. Three different time constants can be clearly distinguished in the plot of counter No. 1, corresponding to the half-life values equal to $4.7 \mathrm{~d}, 8.7 \mathrm{~d}$, and $37.0 \mathrm{~d}$. Decrease of background of units No. 2 and 3 in May can be described by a single decay law with half-life values equal respectively to $7.4 \mathrm{~d}$ and $7.8 \mathrm{~d}$. The contamination of units No. 2 and 3 and the medium-term contamination of unit No. 1 should thus be ascribed to ${ }^{131} \mathrm{~J}$ with a half-life equal to $8.1 \mathrm{~d}$, produced in fission of ${ }^{235} \mathrm{U}$ with yield $\mathrm{r}=2.9 \%$ (Kimel \& Mashkovich, 1966). The shortterm component in unit No. 1 was probably caused by ${ }^{133}$ Xe with a half-life equal to $5.3 \mathrm{~d}$ and $\mathrm{r}=1.9 \%$ and ${ }^{132} \mathrm{Te}$ (half-life $3.2 \mathrm{~d}, \mathrm{r}=4.4 \%$ ). There are four products of induced fission of ${ }^{235} \mathrm{U}$ with half-lives ranging from 1 to 2 months, which could be responsible for the long-term component in unit No. 1. These nuclides include ${ }^{89} \mathrm{Sr},{ }^{91} \mathrm{Y},{ }^{95} \mathrm{Zr}$, and ${ }^{103} \mathrm{Ru}$, their total abundance in products of ${ }^{235} \mathrm{U}$ fission is close to $20 \%$.

Systematic measurements of the background counting rate of counter No. 3, after careful cleaning of the whole unit, indicate that it was stable during June and July, at the level of $2.10 \pm 0.05 \mathrm{cpm}$. Preliminary measurements of the total gamma radioactivity of dust from an electrostatic dust collector installed near the counters have shown high radioactivity of dust particles. Most likely the large increase of background in counter No. 1 was caused by dust particles trapped at the HV connections at the end of the proportional counter.

\section{REFERENCES}

Kimel, L R and Mashkovich, V P, 1966, Zashchita ot ionizirujushchih izluchenii: Moskva, Atomizdat, p 47-49.

Pazdur, A, Awsiuk, R, Bluszcz, A, Pazdur, M F, Walanus, A and Zastawny, A, 1982, Gliwice radiocarbon dates VII: Radiocarbon, $v 24$, no. 2, p 171-181.

Walanus, $\mathrm{A}, 1986, \mathrm{~A}^{14} \mathrm{C}$ electronic measurement system with a micro-computer, in Stuiver, $\mathrm{M}$ and Kra, R S, eds, Internatl ${ }^{14} \mathrm{C}$ conf, 12th, Proc: Radiocarbon, v 28, no. 2A, p 569570 